\title{
Documenta
}

Entre ensaios e transformações no processo criativo do espetáculo Rei David (2012) com Hugo Rodas

Angélica Beatriz Souza e Silva

Revista do Laboratório de Dramaturgia - LADI - UnB - V. 2 e 3, Ano 1 


\section{Entre ensaios e transformações no processo criativo do espetáculo Rei David (2012) com Hugo Rodas.}

Angélica Beatriz Souza e Silva

Resumo: Este artigo apresenta algumas discussões sobre o processo criativo de Hugo Rodas na montagem do espetáculo Rei David, com roteiro e músicas de Marcus Mota, apresentado em 2012 em Brasília. O foco consiste em analisar a condução dos ensaios, a relação de direção de Rodas com o elenco e as transformações que se sucederam construção do espetáculo.

Palavras-Chave: Rei David (2012); Hugo Rodas, Transformação, Processo Criativo, Ensaio.

Abstract: This article introduces some issues about the creative process of Hugo Rodas during construction of the play King David [Rei David] presented in 2012, in Brasilia. Marcus Mota wrote the script and the songs of the play. The analyses' focus is on the conduction of the rehearsals, the steering relationship of Rodas with the cast and the transformations that followed the construction of the spectacle.

Keywords: King David [Rei David], Hugo Rodas, Transformation, Creative Process, Rehearsal.

\section{Prólogo}

A minha participação no processo de Rei David (2012) teve início juntamente com os ensaios, que começaram em 28 de agosto de 2012. Delimitou-se que os ensaios seriam todas as segundas, terças e quintas-feiras, sempre das 14 às 18 horas, sendo que nas duas semanas antecedentes à estreia teriam ensaios à noite. Foram realizadas dez apresentações, duas por dia, entre 28 de novembro e 02 de dezembro de 2012, no Anfiteatro 09 da Universidade de Brasília - UnB. A montagem foi viabilizada pelo apoio financeiro do Fundo de Arte e Cultura - FAC, do Governo do Distrito Federal - GDF.

Participei do processo de montagem do espetáculo como assistente de ensaio e pesquisadora associada. Ao longo do trabalho fui descobrindo como poderia aproveitar ao máximo esse contato com a criação artística. Para isso, houve o planejamento de coletar o máximo de dados possíveis no decorrer dos ensaios. Desse modo, o levantamento da documentação do processo para as análises são registros compostos por filmagens, fotografias e anotações de todos os ensaios, além dos três ensaios gerais e das dez apresentações realizadas. As filmagens que realizei foram com câmera parada e ao todo so-

1 Graduada em Artes Cênicas na Universidade de Brasília- UnB, mestre em Arte, pela mesma instituição.

2 Este artigo é composto por parte do texto da dissertação: "Abordagens de processos criativos: O teatro de Hugo Rodas" (2014). De Angélica Beatriz e orientação do Prof. Dr. Marcus Mota. 
mavam-se mais de 130 horas de vídeo, 500 fotos e 90 páginas de anotações manuscritas. Posteriormente ainda tive acesso às fotos e aos vídeos de divulgação respectivamente de Clara Braga e Bruno Zararewicz e à filmagem profissional de registro das apresentações de Danilo Borges, com as versões de câmera parada e editada. As análises apresentadas tem como base, principalmente, os documentos que foram coletados, tanto os registros materiais como aqueles que surgiram da vivência que tive.

Reconheço que as análises a serem apresentadas podem conter similaridades com questões gerais de outros processos criativos, a intenção é verificar quais das questões desse trabalho específico se conectam com o que foi discutido anteriormente. Verificando assim, como se concretizou o fazer artístico de Rodas nesse processo específico.

Neste texto tratarei sobre a estrutura do espetáculo, a elaboração do roteiro inicial e da composição da equipe que participou do espetáculo.

A equipe composta para a realização dessa montagem envolve diversos artistas além de Rodas, Mota e o orquestrador Marcello Dalla; para a realização do espetáculo também houve a participação da Orquestra Brasília Big Band e Convidados, composta por trinta e nove pessoas mais o regente de orquestra, Ademir Júnior; o coro Laugi e Convidados, com doze integrantes mais o regente Paulo Santos; o elenco com vinte atores cantores; o núcleo de figurino e cenografia; as equipes técnica e de produção com dezoito pessoas. Ao todo a equipe engloba oitenta e nove pessoas.

O resultado do material elaborado por mota, que é utilizado como roteiro inicial do espetáculo é composto por quatorze cenas, em que música e texto se intercalam na construção da obra. Para ilustrar como esse material se organizou segue o quadro que apresenta a estrutura desse roteiro: 


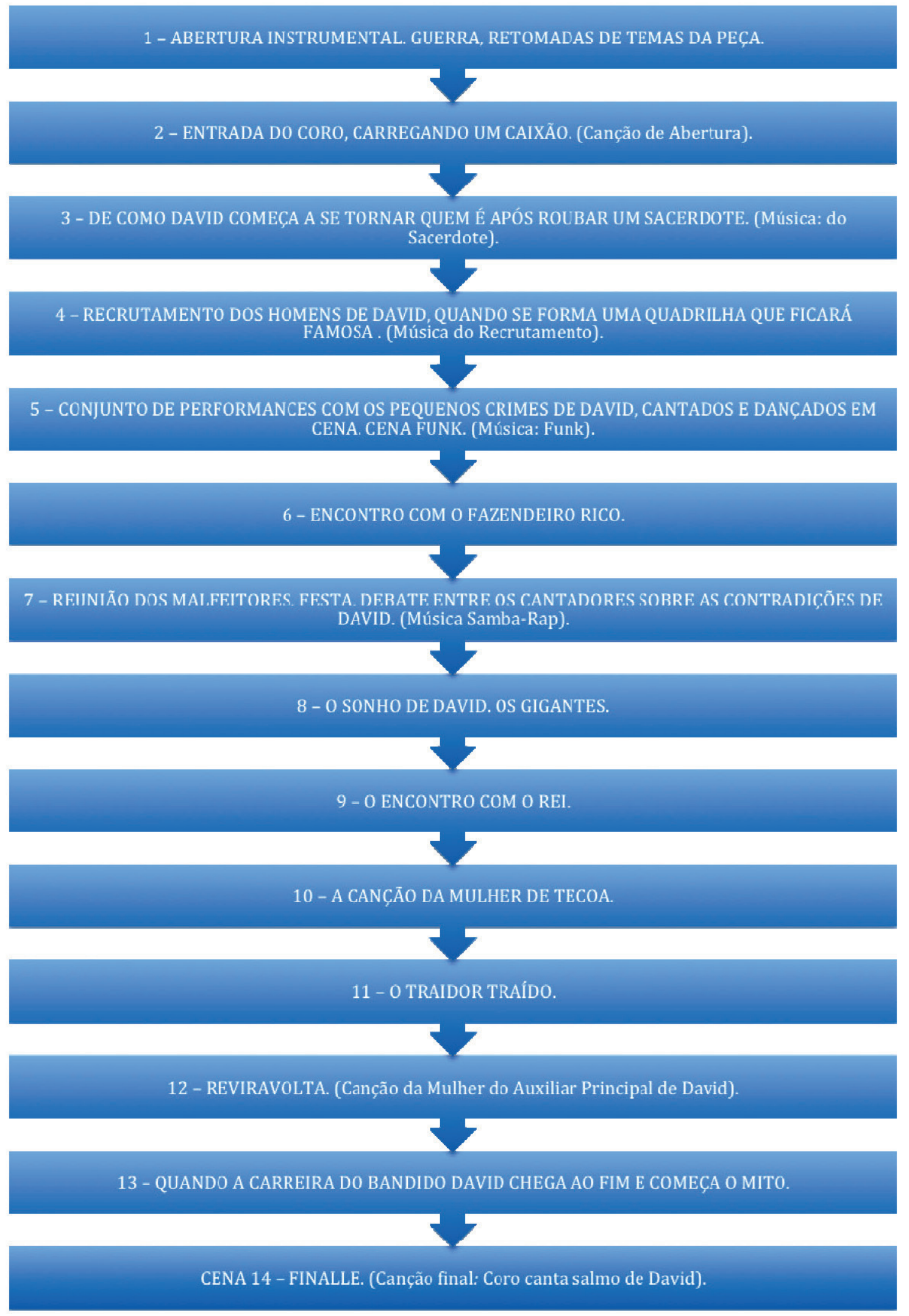

A imagem acima resume a proposta do roteiro inicial do espetáculo. Desse material, ressalto que as cenas: 1 , 2, 4, 5, 7, 10 e 14 são compostas apenas por músicas; as cenas: 6, 8, 
9, 11 e 13 apenas por texto; e as cenas 3 e 12, por músicas e texto. Assim, para montagem desse espetáculo temos um texto que explora as relações entre partes musicais, textuais e mistas.

Essa organização do material foi a base para o início dos trabalhos, entretanto, ao longo dos ensaios diversas mudanças aconteceram até que tivéssemos a estrutura final do roteiro utilizada nas apresentações do espetáculo. Ao acompanhar esse processo notei que mesmo tendo registrado todos os ensaios, parte do que moveu Rodas e o grupo a realizar as alterações é impossível de ser documentado. Essa parte inacessível corresponde às associações mentais como também a uma série de verificações e transformações encadeadas que não podem ser acompanhadas em sua totalidade. Do mesmo modo, como mencionado antes por Ostrower, algumas questões do processo só podem ser vistas e entendidas quando acontecem.

\section{Os ensaios}

Acompanhei a equipe como pesquisadora associada, e ensaiadora. Após essa experiência no processo, procurei rever os materiais coletados com um outro olhar, tentei reunir os momentos decisivos no processo que podem contribuir para a compreensão de alguns aspectos da organização do coletivo realizada por Rodas neste processo criativo. Busco retomar o que essa relação com o grupo possui de importante para um trabalho criativo. Neste texto, a criatividade é entendida como um processo em que o imaginado, no campo das ideias, concretiza-se passando pelo formar, pelo transformar, por testes e verificações. Segundo De Masi (2003) para que isso aconteça em um grupo é preciso uma liderança que contribua para uma dinâmica de equilíbrio do coletivo e leve o trabalho a se desenvolver em uma espiral positiva. Partindo desse entendimento, para compreender um pouco mais sobre o processo criativo de Rodas, ressalto como foi o seu trabalho em relação ao coletivo, para que se estabelecessem essas vertentes dentro da equipe de Rei David.

Enquanto proposta para as análises separarei as observações por semanas. A seleção desse material teve como foco destacar, em cada semana, quais foram as principais decisões e direcionamentos de Rodas no processo. Para organizar esse material, entre as quatorze semanas de trabalho, optei por separar os ensaios em três momentos, sendo o inicial composto pelos primeiros ensaios até a quarta semana. Logo após, vem o desenvolvimento, uma maior parte do trabalho, da semana 5 à semana 11. Por último, as semanas finais, quando aconteceu o acabamento do trabalho, nas semanas de 12 a 14 .

Essa divisão é uma proposta simples na qual se verifica o início, o desenvolvimento e a finalização do trabalho ao longo dos ensaios. Nas discussões sobre as propostas que analisam a separação dos processos criativos em etapas ${ }^{3}$, a maioria dos autores como Graham Wallas (1926), Domenico De Masi (2003) Alencar Fleith (2009) e Fayga Os-

3 As analises sobre as etapas do processo criativo podem ser vistas com mais detalhes no Capítulo 2- Processo Criativos, item 2.2- Em Etapas, na dissertação: "Abordagens de processos criativos: O teatro de Hugo Rodas" (2014). 
trower (1987); concordavam na existência das fases de preparação, incubação, iluminação e verificação. Na minha percepção sobre processos criativos, elas podem acontecer de modo diferenciado em cada processo e tanto num campo micro, como macro. $\mathrm{Ou}$ seja, no processo acompanhado, observo que a cada ensaio existiam diferentes momentos em que aconteciam cada uma dessas fases. Ao mesmo tempo, é possível observá-las por uma abordagem mais ampla considerando o processo como um todo. Desse modo, teríamos alguns ensaios em que a característica mais presente foi a de preparação ou a de verificação. Nos ensaios de Rei David, por corresponder a um processo criativo de um espetáculo, essas fases eram relacionadas principalmente ao trabalho com as cenas e consequentemente aos integrantes do grupo que atuavam nelas.

A partir das análises realizadas, identifiquei algumas especificidades do que seriam as etapas mais gerais do processo acompanhado - envolvendo uma preparação, desenvolvimento, e finalização. Notei que no bloco das quatro primeiras semanas, o foco do trabalho de Rodas foi em relação ao grupo que compunha o elenco. Enquanto que no desenvolvimento do processo aconteceram muitas mudanças e transformações no espetáculo. Assim, temos esses dois períodos principais para desenvolver as análises: 1- a relação de Hugo Rodas com o elenco nesse período inicial do processo, e 2- a transformação ao longo do processo com Rodas.

\section{Rodas e o Elenco}

De acordo com as observações dos registros coletados ao longo do processo criativo, em uma visão geral, Rodas não estava apenas em contato com o elenco. Verifiquei que a sua direção era exercida em diversos níveis, ele não direcionava apenas os atores, mas seu comando interferia em toda a estrutura do espetáculo.

Assim, para compartilhar uma visão mais organizada acerca do posicionamento de Rodas nesse trabalho, organizei as relações em cinco partes:

1. Elenco, composto pelos atores e cantores;

2. Música, que envolve os aspectos musicais do trabalho como também a relação com o orquestrador Marcello Dalla, com a orquestra Big Band e com o coro Laugi;

3. Texto, relacionado às questões de dramaturgia;

4. Questões de cenários e figurinos;

5. Produção, relacionado ao diálogo de Rodas e à equipe de produção.

Ressalto que a relação de Rodas com cada um desses elementos não era isolada, todos eles estavam interligados entre si. Desse modo, as decisões criativas sobre o texto interferiam no elenco, na cenografia, nas músicas e na produção. Rodas é a figura central do processo, e todos os outros elementos estão ao seu redor e interconectados. No primeiro momento o foco foi na relação do diretor com o elenco, composto pelos atores principais e o coro cênico. A orquestra e o coro tradicional participaram apenas do último mês de ensaios.

Assim, o primeiro foco é sobre como Rodas administrou a heterogeneidade do grupo 
que compõem o elenco e os apontamentos que ele indica para a equipe sobre os principais aspectos de seu trabalho.

Com os arquivos em mãos, verifico que, na primeira semana, o elenco teve contato com o roteiro e com as canções. A produção distribuiu cópias dos textos e CDs com as primeiras versões das músicas. No começo do processo, Mota também compartilhou com os integrantes a proposta do espetáculo, a estrutura do drama musical e apresentou cada uma das cenas. Além disso, apresentou sua perspectiva de autor, mencionou o contato com as ideias de Finkelstein e o trabalho de elaboração e reelaboração do texto.

Rodas, por sua vez, comentou as suas ideias iniciais de cenografia, que incluíam uma rampa e uma plataforma - pensadas especificamente para o espaço do teatro Nacional - e figurinos versáteis, com possibilidades de se transformarem em diferentes vestimentas. Ele apontou ainda o filme Espartalhões ${ }^{4}$ como uma referência para o trabalho a ser realizado. A sátira desse filme consiste na reapresentação das principais cenas do filme $300^{5}$ em tom sarcástico e cômico. Como exemplo, os guerreiros são escolhidos não pela sua força e habilidade, e sim pela beleza física e pelo bronzeado, além disso, entre os inimigos que enfrentam, estão o Motoqueiro Fantasma, Rocky Balboa, os Autobots e um corcunda, Paris Hilton e Britney Spears.

Assim, Rodas imagina que a proposta da releitura do mito bíblico, ao ressaltar David e os membros de seu bando por meio de sátiras ${ }^{6}$, apresenta uma outra perspectiva dos fatos. Rodas expõe para o grupo suas ideias, ainda que não estejam concretizadas, mas já mostra por qual caminho pretende seguir na próxima etapa de verificação e teste dessas propostas. Observo que compartilhar essa primeira imaginação sobre o que iria compor o espetáculo permite que Rodas se aproxime do elenco, e são os primeiros traços de como ele administra sua Liderança de Grupo - LG, e busca a troca de conhecimentos e propostas.

Identifico, contudo, que existe uma dualidade nessa liderança de Rodas. Por um lado, conforme apresentado sobre o grupo Pitú e os trabalho com Figueroa, estabelecia uma relação de grupo-comunidade ${ }^{7}$, enquanto nesse primeiro compartilhamento das ideias

4 Título original: Meet the Spartans. Título em português: Espartalhões. Ano de lançamento 2008. Direção: Jason Friedberg, Aaron Seltzer. Roteiro: Jason Friedberg, Aaron Seltzer. Breve sinopse: Um paródia do filme "300" lançado em 2006 com direção de Zack Snyder. Em Espartalhões, o rei Leônidas forma um exército com apenas 13 guerreiros para enfrentar a invasão Persa. Fonte: International Movie Database. Disponível em: <http://www.imdb.com/title/tt1073498/?ref_=ttmd_md_nm> Acesso em: 30 outubro 2013.

5 Título original: 300. Ano de Lançamento: 2006. Direção: Zack Snyder. Roteiro: Zack Snyder, Kurt Johnstad, Michael Gordon. Breve sinopse: O filme aborda a historia da batalha de Termópilas, em que o Rei Leônidas e 300 homens seguem para lutar contra a invasão persa. Disponível em: < http://www.imdb.com/title/tt0416449/?ref_=ttfc_fc_tt> Acesso em: 27 novembro 2013.

6 Os aspectos do cômico e do grotesco no trabalho de Hugo Rodas são observador por Claudia M. Souza em sua dissertação de mestrado: "O Garoto de Juan Lacaze, Invenções no teatro de Hugo Rodas” (2007), e não serão desenvolvidos neste trabalho.

7 - Mais informações sobre os trabalhos de Rodas e Figueroa e o "grupo-comunidade" na dissertação de Souza (2007). 
com o grupo de Rei David ele se mostra centralizador, no sentido de concentrar sobre si as decisões sobre o que pretendia para o trabalho e já apresentando algumas definições sem antes ter um espaço de discussão ou de estabelecer o contato com o grupo para que as resoluções fossem conjuntas. Estou ciente que essa comparação é entre grupos que trabalharam juntos por muito tempo e o grupo que se uniu para um espetáculo específico. Ainda assim, nesse momento que Rodas compartilha com o grupo as suas ideias, ele mostra que em sua mente ele tem uma proposta para o espetáculo, mas não algo totalmente decidido do início ao fim. Como o próprio artista afirmará na entrevista concedida em 31 de outubro de 2014, ele se permite transformar a partir do contato que estabelece com o grupo. É justamente essa mudança que observei ao longo das semanas iniciais. A relação de Rodas com o grupo se modifica a partir das trocas e contatos com os integrantes.

Esses outros relacionamentos que surgem entre Rodas e o grupo também podem ser associados às questões que Robinson (2010) e De Masi (2003) discutem sobre processos criativos em coletivos. Observo que as "tribos" que Robinson (2010) aponta, aproximam da experiência do grupo-comunidade, das pessoas que se encontram pela afinidade em seus domínios e suas buscas, compartilham interesses nos mesmos fazeres e se apoiam. Enquanto os grupos criativos segundo De Masi (2003) e as equipes criativas de Robinson (2010) são mais próximo desse formato de grupo que se une para um determinado trabalho e englobam pessoas com habilidades distintas, mas empenhadas em um mesmo trabalho, seja por um período de tempo que os integrantes determinarem ou até finalizarem um projeto.

A correspondência entre o que os autores identificam em trabalhos de grupos criativos e o que foi observado com a equipe de Rei David também envolve as três características definidas por Robinson (2010): 1) a diversidade, 2) a dinâmica e a 3) identidade distinta.

Interessante notar que os três elementos, a diversidade, a dinâmica e a distinção realmente perpassaram o grupo. No que diz respeito ao primeiro, pude observar que à medida que o grupo se aproximava do senso de grupo, da harmonia, os integrantes com mais facilidade vocal colaboravam indicando notas ou questões específicas musicais. Notei ainda que o grupo se ajuda em relação aos movimentos de cenas - reorganizar como a diversidade, na harmonia adquirida contribuir para o trabalho em grupo, como também para aspectos individuais, além das próprias orientações individuais que Rodas realizava para cada integrante.

Noto que o fato de o coro cênico ter trabalhado com o elenco principal ao longo de todo esse processo de harmonização permitiu que o grupo todo se estabelecesse como um conjunto, no sentido que se desenvolvem tanto enquanto indivíduos como enquanto equipe. Esse trabalho de coletividade teve também sua importância por ser o trabalho que preparava a atuação de um coro, que precisava estar em sintonia, mas o trabalho realizado ultrapassou esse limite. A união que desenvolveram os configura em um grupo com sua identidade distinta, envolvendo tanto o coro cênico como o elenco principal em uma só equipe, como acontece em outros grupos. No processo acompanhado isso refletiu na reorganização da estrutura do espetáculo Rei David.

A proposta inicial determinava cenas separadas para a atuação do coro cênico e do 
elenco principal, posteriormente a esse trabalho para a organização do grupo em equipe criativa, a divisão inicial se dilui. Desse momento em diante, o coro cênico passa a integrar todas as cenas do espetáculo, assumindo diferentes papéis. Por exemplo, na cena 3, seria apenas David e o Sacerdote, mas o coro continua em cena como o "grupo religioso" da cena 2, só que deixam o Sacerdote e passam a apoiar David. Assim, da cena 4 à cena 8, ele compõe o "bando de David", que o acompanham em todas as cenas, não apenas nas que eram estabelecidas inicialmente. A partir da cena 9, são “a corte do rei”. O coro cênico, aliado ao texto e às músicas, passou a ser o elemento condutor do espetáculo.

\section{O trans-formar em processo}

Para falar sobre as transformações, comento também o fato de que existe certa ideia mítica em torno de Hugo Rodas, na qual ele mudará tudo o tempo todo. Vejo diante disso uma preocupação do grupo em acompanhar as mudanças propostas e um receio de que na véspera da estreia tudo seja alterado, levando um sentimento de insegurança aos participantes.

Acompanhando o trabalho de Rodas, a partir do que observei nos ensaios, identifico que ele trabalhava de modo objetivo, apresentando suas ideias para as cenas e seguia para o momento de testes e verificações. Suas propostas se modificavam a partir do contato estabelecido com o grupo, e a decisão do que seria ou não mantido era de Rodas. Perpassando esse processo também investigo como ele busca a harmonia para o grupo. Notei que no primeiro momento de trabalho como a equipe, Rodas já inicia a proposta de concretizar como seria a cena 2 .

O trabalho começou por essa cena, pois a primeira cena seria apenas uma música de abertura, e o elenco só entraria na segunda. A proposta que Rodas apresenta e experimenta com o grupo é que para esta cena a organização do coro fosse em duas fileiras, que entravam cantando e carregando um caixão com David em seu interior. Ao longo do processo, essa proposta foi trabalhada e desenvolvida, mas esses elementos da ideia inicial foram utilizados na apresentação.

Entretanto, antes de seguir para o momento de concretização, com testes e verificações das ideias para as cenas, observo que Rodas muda o direcionamento dos ensaios e segue por outras atividades.

Nesse caminho, no início da segunda semana, dia 06 de setembro de 2012, após um aquecimento, Rodas inicia um trabalho coreográfico com a música da cena 2. Todos os integrantes foram reorganizados no espaço, de modo diferente das duas fileiras e, aproveitando os espelhos da sala de ensaios no Núcleo de Dança da UnB, Rodas propunha diferentes coreografias para a música da cena 2 e todos deveriam seguir.

De início, porém, o grupo não percebe que essa atividade seria um exercício. Rodas sentiu a preocupação do grupo, que imaginava que o diretor estava descartando todo o trabalho anterior e construindo algo totalmente diferente. Diante dessa situação, comentou com o grupo que essa coreografia não substituiria o que havia sido ensaiado anteriormente e não estaria na parte final do espetáculo. Era, no entanto, um trabalho de atenção para observar o corpo e a música. Uma atividade para a "homogeneidade", para aprender 
a estar junto e saber musicalmente se localizar no espaço com o seu corpo.

Com esse acontecimento aponto dois aspectos relevantes. Primeiro, o imaginário que muitos possuíam de que o diretor estaria sempre modificando tudo. Ao longo do processo realmente aconteceram diversas mudanças, contudo não eram mudanças aleatórias. E, ainda que minimamente, eram seguidos alguns princípios, seja do roteiro ou das experimentações conscientes do diretor.

No decorrer do processo criativo o grupo percebeu que as mudanças não seriam como imaginaram naquele momento. $\mathrm{Na}$ entrevista realizada para esta pesquisa, Rodas comenta e esclarece que sempre diz para todos: "eu transformo hasta lo último dia" ${ }^{8}$. Para ele, existem "mudanças que son absolutamente necessárias e que aparecien pela contrución, em la construción, e no em una ideia" . Seguindo nessas reflexões, ao longo da entrevista Rodas menciona que ele não é uma autoridade sobre si - em seu processo de concretizar as ideias, ele não parte apenas de um conceito ou proposta pré-estabelecida, mas pelo que surge no processo de criação. Dialogando sobre como ele se relaciona com as questões das mudanças nesse processo de materializar a imaginação, Rodas afirma:

No so una persona que vá detrás de trabalho que imagino. Eu imagino um trabalho, do começo até o fim. É, em el processo se vá transformando tudo, se transformando tudo, tudo! Como se transforma cada dia, como se transforma su necessidad. (...) Entocés vocie tien que saber, como enfrentar-se com isso. As coisas se transforman lo tiempo inteiro.

Hugo Rodas, entrevista 31, outubro, 2014.

Nisso percebo a consciência dele de que o grupo precisa saber lidar com essas transformações. Observo que no processo criativo de Rodas, as ações e direcionamentos são iniciados a partir das suas propostas idealizadas, contudo ele não as impõe para que seja mantido exatamente o que foi concebido mentalmente, ele permite que se transformem com as outras possibilidades que podem surgir.

Essas reflexões contribuem para esclarecer mais sobre Rodas na condução dos ensaios e as mudanças realizadas ao longo do processo. No início dos ensaios ela já apresenta a proposta pré-estabelecidas das suas ideias sobre o que deve ir para a cena. Todavia, quando suas ideias e propostas são compartilhadas, sua postura se modifica e ele se permite mudar e transformar as imaginações iniciais a partir do que o processo lhe oferece. No caso de Rei David, notei que no momento de concretização entrava o diálogo com o grupo, já estabelecido em sua identidade distinta e juntos trans-formavam, criavam.

Rodas comenta como observa a questão da transformação a partir de algo que surgiu no processo. Para ele:

A obra de arte em si é absolutamente transformadora, ela te transforma. Você tiene que respeitar o que teu próprio trabalho te ensina. É la imagem que es

8 Hugo Rodas, entrevista 31 de outubro de 2014.

9 Idem. 
devolvida pra você, ela que te transforma, ela que te ensina em la realidad. Hugo Rodas, entrevista 31, outubro, 2014.

Quando ele menciona que se deve aprender com o trabalho, associo isso aos Domínios em Processo - DP -, considerando-os como os saberes que se desenvolvem a partir dos retornos que a criação em processo envia. Sempre será uma nova devolução, que exigirá novas reflexões e investigações no processo de formar. Esse retorno da obra ao longo do processo também proporcionará as transformações a que Rodas se refere. Nesse retorno, vejo ainda uma associação com o que Luigi Pareyson (2010) chama de "legalidade interna da obra", que seria o que a obra retorna para Rodas, o que o conduz em seu fazer criativo. Para Luigi Pareyson:

(...) o artista inventa não só a obra, mas na verdade a legalidade interna dela, e a tal legalidade ele é o primeiro a estar submetido. Extremamente livre e criador enquanto cria não somente a obra, mas também a lei que a governa, $\mathrm{e}$ este é o único modo como ela se deve deixar fazer; mas, ao mesmo tempo, vinculadíssimo e sujeito a uma lei inviolável e extremamente severa, que é aquela mesma legalidade que ele desencadeia no ato de conceber a obra: autor e súdito, inventor e seguidor, criador e subalterno, ao mesmo tempo. (2010, p.184).

Ao mencionar essa troca entre criação e criador, vejo que Pareyson comenta sobre como no ato criativo é preciso estar atento ao que a obra te retorna, como Rodas também afirma. Essa prontidão seria necessária para perceber a legalidade da obra e criar em conjunto com ela, pelas transformações que surgem como necessárias na construção da obra. Como para criar é preciso trans-formar, relaciono outro ponto da fala de Rodas ao que Ostrower (1987) comenta, que corresponde à questão de como o contato com a obra é transformador. A relação do novo com a criatividade, durante um processo criativo, estabelece uma ligação entre a obra, e com quem a cria e ambos se transformam pelas ressignificações e reformulações que se fazem nessa troca, como Ostrower (1987) declara que esse novo seria a partir do que cada indivíduo recria para si a cada contato com a obra. Vejo as reformulações e recriações abordadas por Ostrower presentes no processo, não apenas no contato posterior com a obra ou produto criado. Estabelecendo ao longo do percurso criativo a transformação em quem cria e no desenvolvimento da criação.

$\mathrm{Na}$ discussão sobre as mudanças realizadas no processo também retomo que elas não são aleatórias. A arbitrariedade não se relaciona com o fazer criativo, pois não vincula-se ao consciente para essas ações e, sem o consciente, a ação não é criativa. Verifiquei que as modificações eram constantes no decorrer dos ensaios de Rei David, e isso gerava, em alguns, a sensação de incompreensão sobre a razão de tantas mudanças aparentemente aleatórias. Sobre essas questões, Pareyson acrescenta que no percurso criativo existe um princípio condutor que orienta essas mudanças e transformações. Ele afirma que:

Este estado de tateamento e de aventura total é contrário à experiência artística: o decurso do processo artístico é de algum modo orientado, porque o artista mesmo não possuindo nenhum critério objetivo e mesmo não dispondo de um projeto preestabelecido, está em condições de reconhecer e distinguir, 
no curso da produção, aquilo que deve cancelar, ou corrigir, ou modificar, e aquilo que, pelo contrário, está bem conseguido e pode considerar como definitivo (2001, p.187).

No mesmo sentido da abordagem do filósofo, Ostrower (1987) menciona sobre como no percurso de criação todos se seguiam pela a intuição, que para a autora é como uma bússola interior. Mesmo que o próprio criador não a conheça a priori, ela guia as decisões e opções ao longo do percurso, de modo que as escolhas nunca serão aleatórias. Nessas perspectivas relaciono ainda a intuição, no sentido proposto por Ostrower, no qual ela retém os Domínios Antecedentes - DA. Eles poderiam estar até em um estado pouco inconscientes, mas auxiliariam nessas seleções ao longo do ato criativo.

Associo esses pensamentos de Pareyson e Ostrower com o que ocorreu durante o processo. Ainda que a objetividade das decisões não estivessem claras, existia no diretor a consciência do que algo precisava ser modificado, enfatizado ou até mesmo cortado, tanto no nível textual como no musical. Isso sendo estabelecido pela legalidade da obra com o que ela retornava para Rodas, como a sua intuição conduzindo o caminho. Ressalto que essas são minhas percepções a partir do que visualizei no acompanhamento e nos registros dos ensaios, mas sem acesso às reflexões mentais de Rodas.

\section{Epílogo}

Suponho que podemos pensar que algumas mudanças sugeridas podem parecer desprovidas de sentido por não entendermos, ou por não termos acesso ao modo como essas seleções e organizações acontecem na mente de outras pessoas, ou, mesmo em nós. Contudo, Ostrower (1987, p. 75) complementa que mesmo não tendo acesso anterior a essa intuição, as escolhas e os caminho que te conduzirão a sua meta serão visualizados ao longo do percurso, à medida que esse for sendo traçado. Relacionando isso à fala de Rodas, quando ele menciona que 'o retorno' recebido da obra ao longo do processo indicaria as questões de transformação seguindo a legalidade da obra e que essas ações e mudanças permitiriam desvendar alguns aspectos desse caminho que se está percorrendo e traçando ao mesmo tempo.

Ostrower (1985) complementa que essa trajetória apesar de intuitiva é repleta de experimentações. Sem acesso ao campo mental dos artistas do processo, pude ver esses caminhos sendo percorridos pelo que acontecia nos ensaios. Como é característico desse espaço nos processos criativos cênicos, nos ensaios ocorrem os momentos de investigações e as transformações que envolvem o ato de criar.

Sobre o espaço do ensaio, Patrice Pavis, observa que o termo "ensaios" pode configurar-se de formas distintas. A definição que mais aproxima do que se configurava no processo criativo de Rei David são as definições de Peter Brook, em que:

A palavra francesa evoca um trabalho quase mecânico, ao passo que os ensaios se desenvolvem cada vez de maneira diferente, e são, às vezes, criativos. (...) $\mathrm{O}$ alemão Probe ou o espanhol ensayo ("tentativa") traduz melhor a ideia de experimentação e de tateio antes da adoção da solução definitiva (Pavis, 2008, p.129). 
Os ensaios de Rei David eram exatamente o espaço das experimentações. Presenciar e registrar esses momentos contribuiu para as observações sobre o desenvolvimento do processo criativo nesse espaço em que aconteciam os teste e verificações das ideias, bem como as tomadas de decisões que definiram o espetáculo. As escolhas aconteciam pelo processo de experimentação no qual Rodas e o grupo testavam e verificavam as ideias. Isso, por sua vez, levou às transformações do ato de criar. É importante destacar ainda que tanto as canções como os textos foram modificados durante os ensaios. Rodas iniciou o trabalho partindo do roteiro proposto, todavia, ao observar o que era apresentado, reorganizava a ordem dos acontecimentos e parte do material textual e musical.

Rodas também diz que compreende o transformar no sentido de algo da imaginação que se modifica para concretizar e complementa "Una transformacion não é agregar como se fossen adornos, como se fora um brinco, como se fora um colar"10. Diante da afirmação, percebe-se que para o artista, transformar não está nas opções de agregar elementos novos como acessórios, mas no que se verifica e o no que acontece ao longo do processo. Não apenas a inclusão de novos elementos como uma música ou um texto, mas sim como a música e o texto podem ser modificados ao longo do trabalho. São exatamente essas mudanças que abordarei adiante. Como se estabeleceram as alterações no roteiro, que inclui os textos e as músicas das cenas de Rei David. Pude observar isso especialmente na reorganização do roteiro do espetáculo.

Durante as descrições, foi difícil transcrever como ocorram as trans-formações, que é esse fluxo constante entre o formar e o transformar em processo criativo. O mesmo é verificado em Rei David. São sucessões de testes e verificações que se desdobram em outras propostas em um fluxo muito contínuo e próprio do fazer criativo. É possível estabelecer suposições sobre as escolhas e decisões a partir do que foi visto, mas compreendê-las por completo ainda é inacessível. Assim, apresento essas observações para compartilhar um pouco do que foi vivenciado e das reflexões que surgiram, mesmo que elas sejam apenas resquícios de algo muito mais profundo e complexo que envolve o trabalho de Rodas.

\section{Referências}

ALENCAR, Eunice Soriano de; FLEITH, Denise de Souza. Criatividade: Múltiplas perspectivas. Brasília: Editora Universidade de Brasília, 2009.

DE MASI, Domenico. Criatividade e grupos criativos. Rio de Janeiro: Sextante, 2003.

GALE, Maggie B.; FEATHERSTONE, Ann. The Imperative of the Archive: Creative Archive Research. In: KERSHAW, Baz; NICHOLSON, Helen (Ed.). Research Methods In Theatre And Performance. Edinburgh University Press, 2011, pp. 17- 40.

GALIZIA, Luís Roberto. Os processos criativos de Robert Wilson. São Paulo: Perspectiva, 2004.

GARDNER, Howard. Mentes que criam. Porto Alegre: Artes Médicas, 1996.

GOSWAMI, Amit. Criatividade para o século 21: Uma visão quântica para a expansão do

10 Entrevista em 31 de outubro de 2014. 
potencial criativo. São Paulo: Aleph, 2012.

FERNANDES, Sílvia. Memória e Invenção: Gerald Thomas em cena. São Paulo: Perspectiva FAPESP, 1996.

. "Experiências de performatividade na cena brasileira contemporânea".

Brasil: Art Research Journal, Jan./Jun. v. 1, n. 1, pp. 121-132, 2014.

LUBART, Todd. Psicologia da criatividade. Porto Alegre: Artmed, 2007.

KA, Tamara. Memória do Efêmero, O DVD - registro de teatro. São Paulo, Annablume, 2008.

KERSHAW, Baz; NICHOLSON, Helen (Ed.). Research methods in theatre and performance. Edinburgh: University Press, 2011.

MOTA, Marcus. "A discussão da idéia de Espaço em Kant e seu contraponto na teatralidade, a partir de comentário de uma montagem de Hugo Rodas". In: MEDEIROS, Maria Beatriz e MONTEIRO, Mariana F.M.(Orgs.). Espaço e Performance. Brasília: Editora da Pós-graduação em Arte da Universidade de Brasília, 2007. ."Dramaturgia, colaboração e aprendizagem: um encontro com Hugo Rodas". In: VILLAR, Fernando Pinheiro e CARVALHO, Eliezer Faleiros de (Orgs.). Histórias do teatro brasiliense. Brasília: Artes Cênicas - IdA/UnB, p. 198-217, 2004.

. "Teatro, Música e Estranhamento: a dramaturgia e recepção de David". In: Simpósio da Internacional Brecht Society, Porto Alegre: UFRGS, Anais. Vol. $1,2013$.

OSTROWER, Fayga. Criatividade e processo de criação. Petrópolis: Vozes, 1987.

PAREYSON, Luigi. Os problemas da estética. São Paulo: Martins fontes, 2010.

ROBINSON, Ken. O Elemento-chave: Descubra onde a paixão se encontra com seu talento e maximize seu potencial. Rio de Janeiro: Ediouro, 2010.

RODAS, Hugo. MOTA, Marcus. Hugo Rodas. Brasília: Editora ARP Brasil, 2010.

WALLAS, Graham. The Art of Thought. New York: Harcourt, Brace and Co., 1926.

WATSON, Charles. "Pedágio de pensamento". In. ALMEIDA, Cezar de; BASSETTO, Roger (Org.). Sketchbooks: As páginas desconhecidas do processo criativo. São Paulo: Ipsis, pp. 8-9, 2010.

YOUNG, Harvey. "Review of Documentation, Disappearance and the Representation of Live Performance by Matthew Reason". In: Theatre Journal, Vol. 60, Number 2 (May), pp. 316-317, 2008.

Dissertações e trabalhos acadêmicos

SOUZA, Claudia Moreira de. "O Garoto de Juan Lacaze, Invenções no teatro de Hugo Rodas". Dissertação de Mestrado, Programa de Pós-Graduação em Artes/VIS/IdA, Universidade de Brasília - UnB. Brasília, 2007.

\section{Entrevistas}

RODAS, Hugo. Entrevista concedida a esta pesquisadora em 13 de setembro de 2012. RODAS, Hugo. Entrevista concedida a esta pesquisadora em 31 de outubro de 2014. 